\title{
KERAGAAN USAHA BUDIDAYA IKAN NILA (OREOCHROMIS NILOTICUS) DALAM PEMANFATAAN LAHAN PEKARANGAN DI DESA JANTI KECAMATAN POLANHARJO KABUPATEN KLATEN PROVINSI JAWA TENGAH
}

\author{
S. Masithoh ${ }^{1 \mathrm{a}}$, W. Nahraeni ${ }^{1}$, S. Afifah ${ }^{1}$ \\ ${ }^{1}$ Jurusan Agribisnis, Fakultas Pertanian Universitas Djuanda Bogor \\ Jalan Tol Ciawi No. 1 Kotak Pos 35 Bogor 16720 \\ ${ }^{a}$ Korespondensi: Siti Masithoh. Telp: 0817404974; E-mail: smasithoh@ yahoo.com
}

\begin{abstract}
This study was conducted from December 2013 to January 2014. Thirty-five farmers were selected as respondents. These farmers consisted of 10 hatchery farmers, 20 rearing farmers, and 5 fishing pond owners. Results showed that in hatchery business, with a pond size of 440 $\mathrm{m}^{2}$ within 38 day production process, $129.8 \mathrm{~kg}$ nila fish was produced. With a selling price of Rp.31,000/kg, total revenue is Rp.4,049,760. In fish rearing business, with a pond size of 141 $\mathrm{m}^{2}$ within 4 month production process, $815.55 \mathrm{~kg}$ nila fish was produced. With a selling price of Rp.19,850/kg, farmers in this fish rearing business earned a total income of Rp.16,188,668. Meanwhile, in fishing pond business, with an average pond size of $213 \mathrm{~m}^{2}$, farmers could sell their fish by $800 \mathrm{~kg}$ per month. With a selling price of $\mathrm{Rp} .19,850$ per $\mathrm{kg}$, farmers in this fishing pond business earned a total income of Rp.29,600,000. The R/C ratios of fish hatchery, fish rearing, and fishing pond businesses were 1.183, 1.096, and 1.741, respectively indicating that these businesses were all feasible.
\end{abstract}

Key words: home yard, feasibility, income analysis.

\begin{abstract}
ABSTRAK
Penelitian ini dilaksanakan pada bulan Desember 2013 - Januari 2014. Analisis yang digunakan adalah analisis pendapatan. Responden dalam penelitian ini adalah sebanyak 35 petani meliputi 10 petani pembenihan, 20 petani pembesaran dan 5 pemilik usaha pemancingan. Hasil penelitian pada usaha pembenihan dengan luas kolam $440 \mathrm{~m}^{2}$ dapat memproduksi 129,8 kg/38 hari seharga Rp. 31.000/kg dengan penerimaan sebesar Rp. 4.049.760. Pada usaha pembesaran dengan luas kolam $141 \mathrm{~m}^{2}$ dalam satu kali proses produksi yaitu selama 4 bulan, jumlah produksi yang dihasilkan sebesar 815,55 kilogram dengan harga jual Rp. 19.850 per kilogram sehingga petani mendapatkan penerimaan sebesar Rp. 16.188.668. Pada usaha pemancingan dengan luas kolam rata-rata $213 \mathrm{~m}^{2}$ petani dapat menjual sebanyak 800 kilogram per bulan dengan harga jual sebesar Rp. 37.000 per kilogram maka penerimaan yang diterima oleh pemilik pemancingan yaitu sebesar Rp. 29.600.000. Analisis usaha budidaya ikan nila per satu kali panen dilihat dari nilai R/C rasio pada usaha pembenihan, pembesaran dan pemancingan secara berurutan yaitu 1,183, 1,096 dan 1,741 sehingga usaha budidaya ikan nila yang dilakukan di Desa Janti menguntungkan dan layak untuk diusahakan karena nilai R/C lebih dari satu.
\end{abstract}

Kata kunci: lahan pekarangan, layak, analisis pendapatan. 


\section{PENDAHULUAN}

Pembangunan subsektor perikanan menjadi salah satu agenda penting dari pembangunan pertanian, pemanfaatannya telah meluas ke seluruh wilayah Indonesia termasuk di Kabupaten Klaten. Sub sektor perikanan di Kabupaten Klaten memiliki laju pertumbuhan positif yang ditunjukkan dengan peningkatan produksi mencapai 50,5 persen selama tahun 2009-2011 (DKP Klaten, 2011).

Kecamatan Polanharjo merupakan salah satu kecamatan di Kabupaten Klaten yang mempunyai jumlah produksi ikan terbesar yaitu pada lahan kolam sebesar 72.281 kuintal dan karamba sebesar 450 kuintal dengan produksi yang terus mengalami peningkatan secara kontinyu. Selain itu, tersedianya sumberdaya air yang melimpah menjadikan kecamatan Polanharjo dapat dikembangkan menjadi sentra perikanan budidaya ikan.

Berdasarkan survei pendahuluan, salah satu desa di Kecamatan Polanharjo yang lahan pekarangannya sudah dimanfaatkan untuk beberapa usaha budidaya ikan nila adalah Desa Janti. Desa Janti memiliki luas kolam $61.935 \mathrm{~m}^{2}$ dengan produksi ikan nila sebesar 48.084 $\mathrm{Kg}$. Beragam usaha budidaya ikan nila yang dilakukan di Desa Janti yaitu diantaranya usaha pembenihan, pembesaran dan pemancingan. Seluruh kegiatan tersebut dilakukan di lahan pekarangan.

Usaha budidaya yang dilakukan oleh petani umumnya tidak dikelola dengan manajemen yang baik. Hasil usaha dan keperluan rumah tangga untuk keperluan sehari-hari sering tidak dikelola dengan baik, sehingga pendapatan bersih dari kegiatan usaha budidaya ikan tidak diketahui dengan jelas. Hal ini membuat petani tidak mengetahui dengan jelas berapa pendapatan usaha yang dihasilkan dari kegiatan budidaya ikan. Oleh karena itu, penting untuk dilakukan penelitian mengenai perhitungan pendapatan usaha budidaya ikan nila di Desa Janti Kecamatan Polanharjo Kabupaten Klaten.
Penelitian ini bertujuan untuk mengetahui dan menganalisis:

1. Keragaan usaha budidaya ikan nila dalam pemanfaatan lahan pekarangan.

2. Besarnya pendapatan usaha pembenihan, pembesaran dan pemancingan ikan nila dalam pemanfaatan lahan pekarangan.

3. Kelayakan usaha pembenihan, pembesaran dan pemancingan ikan nila dalam pemanfaatan lahan pekarangan.

\section{BAHAN DAN METODE}

\section{Konsep Usahatani}

Ilmu usahatani didefinisikan sebagai ilmu yang membahas bagaimana manusia atau individu mengusahakan dan mengalokasikan berbagai faktor-faktor produksi sebagai modal (Suratiyah, 2009). Menurut Soekartawi (2006) aspek-aspek pokok suatu kegiatan usahatani terdiri atas : penerimaan, biaya, perhitungan $\mathrm{R} / \mathrm{C}$ rasio dan Analisis titik impas (Break Even Point) .

\section{BAHAN DAN METODE}

Penelitian ini dilaksanakan di Desa Janti Kecamatan Polanharjo Kabupaten Klaten Provinsi Jawa Tengah. Populasi responden merupakan petani yang membudidayakan ikan nila dalam memanfaatkan lahan pekarangannya sebagai tempat budidaya. Jumlah responden sebanyak 35 petani meliputi 10 petani usaha pembenihan, 20 petani usaha pembesaran dan 5 pemilik usaha pemancingan ikan nila. Teknik sampling yang digunakan yaitu teknik snowball sampling. Data yang telah diperoleh kemudian di analisis dengan dua cara yaitu secara kuantitatif dan kualitatif.

\section{Analisis Penerimaan}

Penerimaan yang diperoleh dari usaha pembenihan, pembesaran dan pemancingan ikan nila dinyatakan dalam :

$$
\mathrm{TR}_{\mathrm{i}}=\mathrm{Y}_{\mathrm{i}} \cdot \mathrm{Py}_{\mathrm{i}}
$$


Keterangan:

$\mathrm{TR}_{\mathrm{i}} \quad=$ Penerimaan total usaha $(\mathrm{Rp})$

$\mathrm{Y}_{\mathrm{i}} \quad=$ Produksi $(\mathrm{Kg})$

$\mathrm{Py}_{\mathrm{i}} \quad=$ Harga output $(\mathrm{Rp})$

\section{Analisis Biaya}

Biaya yang dikeluarkan dari usaha pembenihan, pembesaran dan pemancingan ikan nila dinyatakan sebagai:

Keterangan:

$$
\mathrm{TC}=\mathrm{FC}+\mathrm{VC}
$$

$\mathrm{TC}=$ Biaya Total usaha $(\mathrm{Rp})$

FC = Biaya Tetap usaha ikan nila (penyusutan alat-alat dan penyusutan pembuatan kolam) (Rp)

$\mathrm{VC}=$ Biaya Tidak Tetap usaha ikan nila (benih, tenaga kerja, pupuk kandang dan pakan) (Rp)

\section{Analisis Pendapatan}

Pendapatan yang diperoleh dari usaha pembenihan, pembesaran dan pemancingan ikan nila dinyatakan sebagai:

Keterangan:

$$
\Pi=\mathrm{TR}-\mathrm{TC}
$$

$\pi \quad=$ Pendapatan bersih usaha (Rp)

$\mathrm{TR}=$ Penerimaan total usaha $(\mathrm{Rp})$

TC = Biaya total usaha (Rp)
Analisis R/C rasio

Nilai R/C rasio dari usaha pembenihan, pembesaran dan pemancingan dinyatakan sebagai :

$$
\mathrm{R} / \mathrm{C}=\mathrm{TR} / \mathrm{TC}
$$

Keterangan:

$\mathrm{R} / \mathrm{C}=$ Rasio biaya penerimaan usaha (Rp)

$\mathrm{TR}=$ Penerimaan total usaha $(\mathrm{Rp})$

$\mathrm{TC}=$ Biaya total usaha $(\mathrm{Rp})$

\section{HASIL DAN PEMBAHASAN}

\section{Kondisi Wilayah Kabupaten Klaten}

Kabupaten Klaten secara geografis terletak antara $110^{0} 26^{\prime} 14^{\prime \prime}$ $110^{\circ} 48^{\prime} 33$ " Bujur Timur dan $7^{0} 32^{\prime} 19^{\prime \prime}-$ 7048'33" Lintang Selatan. Kabupaten Klaten berada diantara 3 kota besar yaitu Yogyakarta, Surakarta dan Semarang yang telah dihubungkan dengan jalur transportasi yang cukup memadai.

\section{Karakteristik Petani Sampel}

Berdasarkan hasil kuisioner kepada 35 petani yang memanfaatkan lahan pekarangannya untuk usaha budidaya ikan nila dapat dijelaskan beberapa karakteristik yang terlihat. Tabel 1 menunjukan karakteristik petani sampel.

Tabel 1. Karakteristik Petani Usaha Budidaya Ikan Nila di Desa Janti, 2013

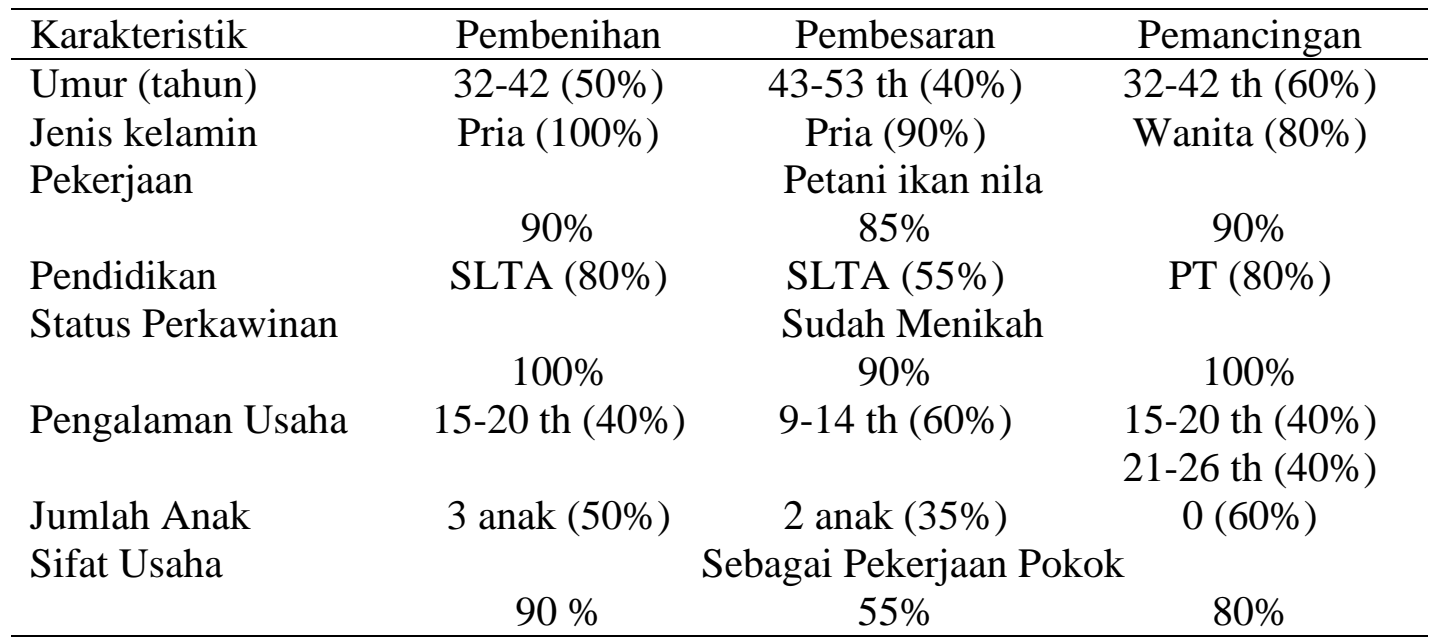

Analisis Usaha Budidaya Ikan Nila

Rata-rata biaya tetap total usaha pembenihan ikan nila dalam satu kali proses pembenihan dengan luas kolam 440 $\mathrm{m}^{2}$ adalah Rp. 1.466.275,- dan rata-rata biaya variabel total sebesar Rp.1.957.363,Rata-rata biaya total yang dikeluarkan oleh petani adalah sebesar Rp. 3.423.638,- 
dengan rata-rata penerimaan yaitu sebesar Rp. 4.049.760,-. Rata-rata pendapatan petani per satu kali proses pembenihan yaitu sebesar Rp. 626.123,- dan nilai R/C yang diperoleh dalam usaha pembenihan ikan nila adalah 1,183. Hal ini menunjukkan bahwa setiap Rp.1.000.000 biaya yang dikeluark memberikan penerimaan sebesar Rp. 1.183.000,Analisis usaha pembenihan ikan nila dapat dilihat pada Tabel 2 .

Tabel 2. Analisis Pendapatan dan R/C Rasio Usaha Pembenihan Ikan Nila di Desa Janti, 2013

\begin{tabular}{|c|c|c|c|c|c|}
\hline No & Uraian & Volume & Satuan & $\begin{array}{c}\text { Harga } \\
\text { per Unit } \\
(\mathbf{R p}) \\
\end{array}$ & $\begin{array}{c}\text { Jumlah } \\
\text { (Rp) }\end{array}$ \\
\hline \multirow[t]{5}{*}{1.} & Biaya Tetap & & & & \\
\hline & a. Biaya Tenaga Kerja & 38 & $\mathrm{HOK}$ & 30.500 & 1.159 .000 \\
\hline & b. Penyusutan Alat-alat & & & & 38.942 \\
\hline & c. Penyusutan Kolam & & & & 268.333 \\
\hline & Biaya Tetap Total & & & & 1.466 .275 \\
\hline \multirow[t]{5}{*}{2.} & Biaya Variabel & & & & \\
\hline & a. Pakan & 5,55 & sak & 264.750 & 1.469 .363 \\
\hline & b. Induk & 12 & $\mathrm{Kg}$ & 24.000 & 288.000 \\
\hline & c. Pupuk Kandang & 20 & Sak & 10.000 & 200.000 \\
\hline & Biaya Variabel Total & & & & 1.957 .363 \\
\hline 3. & Produksi Ikan Nila & 129,8 & $\mathrm{Kg}$ & 31.200 & 4.049 .760 \\
\hline 4. & Penerimaan & & & & 4.049 .760 \\
\hline 5. & Biaya Total & & & & 3.423 .638 \\
\hline 6. & Pendapatan & & & & 626.123 \\
\hline 7. & BEP Penerimaan & & & & 2.819 .759 \\
\hline 8. & BEP Produksi (Kg) & & & & 90,95 \\
\hline 9. & BEP Harga $(\mathrm{Rp} / \mathrm{Kg})$ & & & & 26.445 \\
\hline 10. & $\mathrm{R} / \mathrm{C}$ rasio & & & & 1,183 \\
\hline
\end{tabular}

Sumber: Data Primer, 2013 (diolah).

Berdasarkan tabel 3 menunjukkan bahwa rata-rata biaya tetap total usaha pemancingan ikan nila per bulan di Desa Janti yaitu sebesar Rp. 1.986.250,- dan rata-rata biaya variabel total sebesar Rp.15.019.500,- sehingga rata-rata biaya total yang dikeluarkan oleh pemilik usaha pemancingan per bulan dengan rata-rata luas kolam seluas $213 \mathrm{~m}^{2}$ yaitu sebesar Rp.17.005.750,- dengan rata-rata penerimaan yaitu sebesar Rp. 29.600.000, Rata-rata pendapatan pemilik usaha pemancingan per bulan yaitu sebesar $\mathrm{Rp}$. 12.594.250,- dan nilai $\mathrm{R} / \mathrm{C}$ yang diperoleh pemilik usaha pemancingan adalah 1,741. Hal ini menunjukkan setiap Rp. $1.000 .000,-$ biaya yang dikeluarkan pemilik usaha pemancingan ikan nila yang dilakukan memberikan penerimaan sebesar Rp. 1.741.000,-.

Tabel 3.Analisis Pendapatan dan R/C Rasio Usaha Pemancingan Ikan Nila di Desa Janti,2013

\begin{tabular}{lcccc}
\hline No Uraian & Volume & Satuan & $\begin{array}{c}\text { per Unit } \\
(\text { Rp) }\end{array}$ \\
\hline \hline
\end{tabular}

1. Tetap Biaya
a. Biaya Tenaga Kerja
35 HOK $\quad 38.000$
1.330 .000 
b. Penyusutan Alat-alat

106.250

c. Penyusutan Kolam

550.000

Biaya Tetap Total

1.986 .250

2. Biaya Variabel
a. Pakan
b. Ikan Nila Konsumsi
c. Bumbu
d. Gas
e. Minyak Goreng
Biaya Variabel Total

$\begin{array}{rc}5 & \mathrm{sak} \\ 670 & \mathrm{~kg} \\ 1 & \mathrm{~kg} \\ 6 & \text { tabung } \\ 60 & \text { liter }\end{array}$

260.000
19.250
12.000
15.000
12.000

1.300 .000

12.897 .500

12.000

90.000

720.000

15.019 .500

3. Produksi Ikan Nila

$800 \quad \mathrm{~kg}$

37.000

29.600 .000

29.600 .000

17.005 .750

5. Biaya Total

12.594 .250

6. Pendapatan

4.729 .167

7. BEP Penerimaan

8. BEP Produksi $(\mathrm{Kg})$

9. BEP Harga $(\mathrm{Rp} / \mathrm{Kg})$

1,741

Sumber: Data Primer, 2013 (diolah).

Berdasarkan tabel 4 dapat diketahui bahwa rata-rata biaya total usaha pembesaran ikan nila dalam satu kali proses pembesaran dengan luas kolam $141 \mathrm{~m}^{2}$ adalah sebesar Rp. 14.776.721, rata-rata penerimaan yang diperoleh petani pembesaran yaitu sebesar Rp. 16.188.688,- dengan nilai $\mathrm{R} / \mathrm{C}$ rasio usaha pembesaran sebesar 1,096. Hal ini menunjukkan setiap Rp. 1.000.000,- biaya yang dikeluarkan pemilik usaha pemancingan ikan nila yang dilakukan memberikan penerimaan sebesar Rp. 1.096.000,-.

Tabel 4. Analisis Pendapatan dan R/C Rasio Usaha Pembesaran Ikan Nila di Desa Janti, 2013

No Uraian $\quad$ Volume Satuan $\begin{array}{cc}\text { Harga per } \\ \text { Unit }(\mathbf{R p})\end{array} \quad \begin{gathered}\text { Jumlah } \\ (\mathbf{R p})\end{gathered}$

1. Biaya Tetap
a. Biaya Tenaga Kerja
120 HOK
30.750
3.690 .000
b. Penyusutan Alat-alat
129.350
c. Penyusutan Kolam
322.917
Biaya Tetap Total

2. Biaya Variabel
a. Pakan
b. Benih
c. Pupuk Kandang

32,675 Sak

258.275

8.439.136

75,330 Kg

28.188

2.123 .374

11,7 Karung

6.167

71.944

Biaya Variabel Total

3. Produksi Ikan Nila

$815,55 \quad \mathrm{Kg}$

19.850

10.568 .985

4. Penerimaan

16.188 .668

16.188 .668

5. Biaya Total 
6. Pendapatan

7. BEP Penerimaan

8. BEP Produksi $(\mathrm{Kg})$

608,1

9. BEP Harga $(\mathrm{Rp} / \mathrm{Kg})$

18.118

10. $\mathrm{R} / \mathrm{C}$ rasio

1,096

Sumber: Data Primer (diolah), Tahun 2013.

\section{Analisis Perbandingan Usaha Budidaya Ikan Nila Dalam Pemanfaatan Lahan Pekarangan}

Pada Tabel 5 menunjukkan bahwa pada usaha pembenihan, tingkat persentasi tertinggi pada pakan sebesar 42,92 persen dari biaya total dan tenaga kerja memiliki tingkat persentasi tertinggi kedua sebesar 33,85 persen dari biaya total. Pada usaha pembesaran, biaya yang paling banyak dikeluarkan oleh petani sebesar 57,11 persen dari biaya total sedangkan sebesar 24,97 persen dimiliki oleh biaya tenaga kerja. Pada usaha pemancingan tingkat persentasi tertinggi dimiliki oleh biaya pembelian benih sebesar 75,84 persen dari biaya total dan sebesar 7,82 persen dimiliki oleh biaya tenaga kerja dari biaya total. Dilihat dari nilai R/C pada kegiatan usaha budidaya ikan nila di Desa Janti menunjukkan bahwa usaha pemancingan memiliki nilai $\mathrm{R} / \mathrm{C}$ lebih besar daripada usaha pembenihan dan usaha pembesaran yaitu secara berturut-turut sebesar 1,183, 1,096 dan 1,741. Sehingga seluruh kegiatan usaha budidaya ikan nila yang dilakukan di Desa Janti layak dan menguntungkan untuk dijalankan karena nilai $\mathrm{R} / \mathrm{C}$ rasio lebih dari 1.

Tabel 5. Analisis Perbandingan Usaha Pembenihan, Pembesaran dan Pemancingan Ikan Nila dengan Luas Kolam 440 m² $^{2}$ dan Lama Pemeliharaan selama 120 Hari. 2013

\begin{tabular}{|c|c|c|c|c|c|c|}
\hline Uraian & $\begin{array}{c}\text { Usaha } \\
\text { Pembenih }\end{array}$ & $(\%)$ & $\begin{array}{c}\text { Usaha } \\
\text { Pembesaran }\end{array}$ & $(\%)$ & $\begin{array}{c}\text { Usaha } \\
\text { Pancingan }\end{array}$ & $(\%)$ \\
\hline \multicolumn{7}{|l|}{ Biaya Tetap } \\
\hline a. Biaya Tenaga Kerja & 3.662 .440 & 33,85 & 11.512 .800 & 24,97 & 10.959 .200 & 7,28 \\
\hline b. Penyusutan Alat-alat & 123.056 & 1,14 & 403.572 & 0,88 & 875.5 & 0,62 \\
\hline c. Penyusutan Kolam & 847.933 & 7,84 & 1.007 .500 & 2,19 & 4.532 .000 & 3,23 \\
\hline Biaya Tetap Total & 4.633 .429 & & 12.923 .872 & & 16.366 .700 & \\
\hline \multicolumn{7}{|l|}{ Biaya Variabel } \\
\hline a. Pakan & 4.643 .186 & 42,92 & 26.330 .103 & 57,11 & 10.712 .000 & 7,64 \\
\hline b. Benih/Induk & 910.08 & 8,41 & 6.624 .928 & 14,37 & 106.275 .400 & 75,84 \\
\hline c. Pupuk Kandang & 632 & 5,84 & 224.467 & 0,49 & 0 & 0 \\
\hline d. Bumbu & & & & & 98.88 & 0,07 \\
\hline e. Gas & & & & & 741.6 & 0,53 \\
\hline f. Minyak Goreng & & & & & 5.932 .800 & 4,23 \\
\hline Biaya Variabel Total & 6.185 .266 & & 32.975 .233 & & 123.760 .680 & \\
\hline Biaya Total & 10.818 .695 & 100 & 33.179 .498 & 100 & 140.127 .380 & 100 \\
\hline Produksi & 12.797.242 & & 46.103 .370 & & 243.904 .000 & \\
\hline Penerimaan & 12.797 .242 & & 50.508 .643 & & 243.904 .000 & \\
\hline Pendapatan & 1.978 .547 & & 4.405 .273 & & 103.776 .620 & \\
\hline $\mathrm{R} / \mathrm{C}$ rasio & 1,183 & & 1,096 & & 1,741 & \\
\hline
\end{tabular}

Sumber: Data Primer (diolah), Tahun 2013. 


\section{KESIMPULAN DAN IMPLIKASI KEBIJAKAN}

\section{Kesimpulan}

Usaha budidaya ikan nila yang dilakukan di Desa Janti terdiri atas usaha pembenihan, pembesaran hingga pemancingan. Seluruh kegiatan usaha tersebut dilakukan di lahan pekarangan rumah, dimana lahan pekarangan ini selalu dialiri air secara terus menerus sepanjang tahun.

Pendapatan yang diperoleh per satu kali panen dari usaha pembenihan ikan nila adalah Rp. 626.123, dan usaha pembesaran adalah Rp. 1.411.946,- sedangkan pada usaha pemancingan besarnya pendapatan $213 \mathrm{~m}^{2}$ yaitu diperoleh sebesar $\mathrm{Rp}$. 12.594.250,- per bulan.

Berdasarkan nilai $\mathrm{R} / \mathrm{C}$ rasio yang diperoleh pada usaha pembenihan sebesar 1,183, usaha pembesaran sebesar 1,096 dan usaha pemancingan sebesar 1,741 sehingga usaha budidaya ikan nila yang dilakukan menguntungkan dan layak untuk diusahakan.

\section{Implikasi Kebijakan}

Perlu adanya peran pemerintah dalam pengembangan usaha untuk memperbaiki mutu teknik budidaya sehingga dapat menghasilkan produksi ikan nila yang maksimal. Salah satu cara yang dapat dilakukan adalah diadakannya kegiatan penyuluhan.

Pakan merupakan biaya yang paling besar tingkat persentasinya terhdapa biaya total budidaya ikan nila. Maka disarankan mencampurkan pakan buatan dan pakan alami yang dapat mengurangi biaya pakan.

\section{DAFTAR PUSTAKA}

Kabupaten Klaten Dalam Angka Tahun 2013. 2013. BPS Kabupaten Klaten.

Kecamatan Polanharjo Dalam Angka Tahun 2013. 2013. BPS Kabupaten Klaten.

Soekartawi. 2006. Analisis Usahatani. Jakarta: UI Press.

Suratiyah. 2006. Ilmu Usahatani. Jakarta: Penebar Swadaya. 